\title{
FORMAS DE PERFECCIONAMIENTO Y MECANISMOS DE REALIZACIÓN DE LA PRENDA SOBRE CRÉDITOS
}

WAYS OF PERFECTING AND FORECLOSURE MECHANISMS OF THE PLEDGE OVER CREDITS

\section{FORMAS DE APERFEIÇOAMENTO E MECANISMOS DE REALIZAÇAO DA PENHORA SOBRE CRÉDITOS}

Juan Luis Goldenberg Serrano ${ }^{7}$

\section{RESUMEN}

La ley $\mathrm{N}^{0} 20.190$ introdujo en nuestro sistema jurídico una nueva regulación de la prenda sin desplazamiento, admitiendo la posibilidad de constitución sobre derechos, especialmente sobre créditos. Alejándose del sistema ordinario del Código Civil, que dispone la notificación al deudor del crédito prendado como requisito de perfeccionamiento del contrato, el nuevo modelo la trata como una mera formalidad de publicidad, cuestión que resuelve una serie de problemas prácticos. Pero las siguientes preguntas son: ¿cómo se estructura la realización de la prenda? y ¿qué particularidades merecen ser destacadas con respecto al régimen consagrado para la prenda ordinaria? Las respuestas deben buscarse, a nuestro juicio, en distinguir las formas de perfeccionamiento del contrato de los métodos de ejecución de la garantía, de modo que las diferencias respecto a las primeras no necesariamente justifican distinciones respecto a los segundos.

Palabras clave: prenda ordinaria, prenda sin desplazamiento, prenda sobre créditos.

${ }^{1}$ Licenciado en Derecho, Pontificia Universidad Católica de Chile. Grado de Salamanca, Universidad de Salamanca. Candidato a doctor en Derecho, Universidad de Salamanca. Calle Villar y Macías 16, 4A, Salamanca, España. Artículo recibido el 2 de diciembre de 2010 y aceptado para su publicación el 20 de enero de 2010. Correo electrónico: jlgoldenberg@usal.es. 


\begin{abstract}
Law $\mathrm{N}^{\mathrm{o}} 20,190$ introduced in our legal system a new regulation for pledges without conveyance, allowing the possibility of creating it over rights, specifically over credits. Detaching form the ordinary system contained in the Civil Code, which provides for the notification of the debtor of the pledged credit as a requirement for the perfection of the lien, the new model treats it as a mere formality of publicity, difference that solves a number of practical problems. But the following questions are how does the new model structure the way in which the security interest shall be foreclosed, and which specialties should be pointed out in reference to the regime provided for the ordinary pledges. The answer shall be fetched, in our opinion, differentiating the manner in which the contract is perfected and the methods for the foreclosure of the security interest, so that any difference regarding the first does not necessarily justify any distinctions regarding the latter.
\end{abstract}

Key words: ordinary pledge, pledge without conveyance, pledge over credits.

RESUMO

A lei $N^{\circ} 20.190$ introduz em nosso sistema jurídico uma nova regulação da penhora sem deslocamento, admitindo a possibilidade de constituição sobre direitos, especialmente sobre créditos. Se afastando do sistema ordinário do Código Civil, que dispõe a notificação ao devedor do crédito penhorado como requisito de aperfeiçoamento do contrato, o novo modelo a trata como uma mera formalidade de publicidade, questão que resolva uma série de problemas práticos. Mas as seguintes perguntas são como se estrutura a realização da penhora, e que particularidades merecem ser destacadas com respeito ao regime consagrado para a penhora ordinária. A resposta deve-se procurar, ao nosso parecer, em distinguir as formas de aperfeiçoamento do contrato dos métodos de execução da penhora, de modo que as diferenças com respeito às primeiras não necessariamente justifiquem distinções a respeito do segundo.

Palavras Chave: penhora ordinária, penhora sem deslocamento, penhora sobre créditos. 


\section{INTRODUCCIÓN}

La prenda sobre créditos es una figura bastante utilizada en el tráfico jurídico, principalmente en supuestos de financiaciones de proyectos y pignoraciones de saldos en cuenta. Su estructura típica se encuentra regulada en el Código Civil (y, luego, en el Código de Comercio) desde la misma lógica de la prenda sobre bienes corporales, requiriendo de la entrega de la cosa para el perfeccionamiento del contrato. El desplazamiento corporal es reemplazado por una traslación ideal, en la que el constituyente queda privado de las facultades de cobro y recepción del pago del crédito.

Pero este razonamiento no satisface toda forma de financiación, dado que muchas veces el constituyente no puede despojarse de la facultad de cobro de sus créditos sin comprometer el desarrollo de sus actividades. Sin embargo, las partes tienen pocas vías de escape, considerando que cualquier intento por evitar tal efecto bien podría poner en duda el perfeccionamiento de la garantía, y que las formas de prenda sin desplazamiento creadas por el legislador a lo largo del siglo pasado tampoco satisfacen esta necesidad, en tanto, pensando en las dificultades del despojamiento de bienes productivos, se centraban en la prenda sobre bienes de naturaleza corporal.

La ley $\mathrm{N}^{\circ} 20.190$, de 5 de junio de 2007, que introduce adecuaciones tributarias e institucionales para el fomento de la industria de capital de riesgo y continúa el proceso de modernización del mercado de capitales (en adelante, la ley $\mathrm{N}^{\mathrm{o}} 20.190$ ), remedia esta carencia, concediendo una nueva regulación sobre el contrato de prenda sin desplazamiento -en general- y permitiendo, expresamente, su constitución sobre derechos. Liberado de la notificación de la prenda al deudor del crédito prendado como requisito constitutivo de la garantía, el constituyente puede mantener la facultad de cobro del crédito mientras no medie el incumplimiento de la obligación principal, a la vez que también se permite la constitución de esta clase de prenda sobre créditos futuros y masas de créditos, sin incrementar irracionalmente sus costos de transacción.

Pero queremos aprovechar la futura entrada en vigencia de tal regulación para detenernos en la lógica de la prenda de créditos en general, y cómo ésta se desdobla en un régimen ordinario y uno sin desplazamiento. Para ello, hemos dividido este trabajo en dos partes, dando cuenta de la lógica de cada normativa y de la forma de perfeccionamiento de cada tipo de prenda. Pero la hipótesis principal será demostrar que las diferencias que tracemos entre ellos, especialmente la naturaleza real o solemne del contrato, no tienen por qué afectar los mecanismos de ejecución de la garantía. Obsérvese, además, que en este análisis pondremos especial atención a la prenda sobre créditos dinerarios, no sólo en consideración 
a que se trata del caso más común en la práctica sino, también, porque ha sido nuestro propio ordenamiento jurídico el que se ha orientado a la regulación de este supuesto, para lo cual basta una simple lectura del artículo 819 del Código de Comercio, el artículo 12 del decreto ley $\mathrm{N}^{\mathrm{O}} 776$, de 1925, sobre realización de la prenda (en adelante, el DL 776) y el artículo 31 del artículo 14 de la ley No 20.190.

\section{DE LA PRENDA ORDINARIA SOBRE CRÉDITOS, SU PERFECCIONAMIENTO Y SU FORMA DE REALIZACIÓN}

\section{a. Lógica de la prenda ordinaria sobre créditos}

El pignus nominis suele citarse como primer antecedente de la constitución de algún tipo de garantía sobre créditos $^{2}$. Sus términos son los que, con muy escasa variación histórica, han seguido plasmándose a través de los tiempos, subsumiéndolo en la categoría de la prenda y sólo propiciando una mención particular en atención a las características especiales del objeto sobre el cual recae la caución ${ }^{3}$. En suma, la "prenda de créditos", como toda prenda clásica, se califica como contrato real de modo que su perfeccionamiento requiere de alguna forma de "desplazamiento" a favor del acreedor prendario. Desplazamiento que, no pudiendo ser físico, requerirá de una formulación especial.

Así encontramos la prenda de créditos en las VII Partidas de Alfonso $\mathrm{X}^{4}$, y así se codifica en la mayor parte de las principales legislaciones europeas (Francia, Italia y Alemania) $^{5}$. En los respectivos cuerpos normativos, la

${ }^{2}$ Revísese el Corpus Iuris Civile en C. 4.39.7, C .8.17.4, y D. 13.7 .18 pr; D .20.1.13.2 y D. 20.1.20. En particular, $D .13 .7 .18$ pr. dispone: "Si convenerit, ut nomen debitoris mei pignori tibi sit, tuenda est a praetore haec conventio, ut et te in exigenda pecunia et debitorem adversus me, si cum eo experiar, tueatur. Ergo si id nomen pecuniarium fuerit, exactam pecuniam tecum pensabis, si vero corporis alicuius, id quod acceperis erit tibi pignoris loco (Paulus)."

${ }^{3}$ En contra, véase Remedios Aranda Rodríguez, La prenda de créditos, Madrid, Marcial Pons, 1996, p. 34 y ss., quien, otorgando una serie de justificaciones históricas del pignus nominis, concluye que se trataba de una cesión limitada o condicionada con fines de garantía.

${ }^{4}$ Partida v, título XIII, ley II, dispone: "Otrosi decimos que todos los debdos que deban à un home, que los puede empeñar à otro con todos los derechos que ha en ellos, et aquel que los rescebiere en peños, puédelos demandar en juicio et fuera de juicio, bien asi como farie aquel á quien los debien et que gelos empeñó...”. De ella consta una nota de Andrés Bello en el Proyecto de Código Civil de 1853.

${ }^{5}$ Cabe advertir que en España -con excepción del Código Civil catalán-la codificación omitió toda referencia a la prenda sobre créditos, dando lugar a sendos debates doctrinales respecto a su admisibilidad y naturaleza jurídica. Sobre lo primero, la cuestión ha quedado 
regulación de esta garantía se sitúa precisamente en los párrafos relativos a la prenda (que, a efectos del presente trabajo, y para su distinción con la prenda sin desplazamiento, denominaremos "prenda ordinaria") ${ }^{6}$. El punto común será que en todos ellos se exige la notificación del deudor del crédito prendado como requisito de perfeccionamiento del contrato, $y$, en consecuencia, del nacimiento del derecho real de prenda. Esta notificación busca que, con motivo de la garantía, el deudor del crédito prendado no pueda realizar un pago liberatorio a su acreedor, sino que aquél deba cumplir su obligación entregando la cosa debida (generalmente, dinero) al acreedor prendario. El desplazamiento antes citado se traducirá, en definitiva, en la privación al titular del crédito de sus facultades más relevantes: la posibilidad de cobro y de recepción del pago de la obligación.

De una simple lectura del artículo 2389 de nuestro Código Civil, se hace evidente la plena recepción de este planteamiento tradicional. La admisión expresa de la "prenda de créditos", ubicándola en el campo de la prenda ordinaria ${ }^{7}$, parece no admitir otra conclusión que, en su virtud, el acreedor prendario adquiere un título para la constitución de un derecho real sobre el crédito ${ }^{8}$. Pero el punto crítico de su régimen especial, basado en la inmaterialidad de su objeto, se refiere a la calificación del mecanismo de desplazamiento del crédito prendado, articulado sobre la base de dos requisitos: la entrega al acreedor prendario del título justificativo del crédito y la notificación de la prenda al deudor del crédito prendado, prohibiéndole el pago en otras manos que las del referido acreedor.

Para el tema que nos interesa, la doctrina y jurisprudencia nacional han aportado dos observaciones útiles. En primer lugar, que las gestio-

zanjada con la expresa admisión de la "prenda de créditos" en la Ley 22/2003, de 9 de julio, concursal, en el contexto del reconocimiento de un privilegio especial. Respecto a su naturaleza jurídica, las teorías han ido desde la construcción tradicional -como prenda calificada en cuanto a su objeto- a su explicación como cesión pro solvendo, que admite la subsistencia del crédito prendado hasta que el crédito principal resulte impago. Véase Ángel Carrasco Perera; Encarna Cordero Lobató y Manuel Jesús Marín López, Tratado de los Derechos de Garantía, Pamplona, Aranzadi, 2008, tomo II, pp. 250-252.

${ }^{6}$ Revísense el artículo 2075 y ss. del Code Civil francés (original); los artículos 1881 y 1886 del Codice Civile italiano de 1865 y los artículos 2800 a 2807 del Codice Civile italiano de 1942; y los §§ 1279 a 1291 del BGB alemán.

${ }^{7}$ Nomenclatura y ubicación que se reitera entre los artículos 816 y 819 del Código de Comercio.

${ }^{8}$ Por este motivo llama la atención que Andrés Bello hiciera referencia al Tratado de la Prenda (Nantissement) de Robert Pothier en una nota del Proyecto de Código Civil 1853, conforme al cual: "Por lo que mira a las cosas incorporales, tales como las deudas activas, no son susceptibles de empeñarse por no poder mediar la tradición real que es de la esencia de este contrato". Robert - Joseph POTHIER, Tratado del contrato de peño, traducido al español con notas de Derecho Patrio por una sociedad de amigos colaboradores, Barcelona, J. Roger Editor, 1845, p. 7. 
nes señaladas conforman requisitos de perfeccionamiento del contrato y no sólo formalidades de publicidad, lo que sitúa a la regulación chilena bajo los mismos esquemas e inconvenientes de la legislación francesa, italiana y alemana. En este sentido, nuestra jurisprudencia ha sostenido expresamente:

"Son elementos constitutivos de la prenda de crédito la entrega del título al acreedor prendario y la notificación por éste al deudor del crédito consignado en el título, prohibiéndole que lo pague en otras manos"9.

Y, luego, que Andrés Bello refirió el requisito de notificación en la prenda a la regulación de la cesión de créditos, lo que, sin embargo, no se refiere a una aproximación a la naturaleza jurídica de la prenda de créditos como derecho personal, sino sólo una referencia a los requisitos para el perfeccionamiento de ambas figuras.

\section{b. Perfeccionamiento de la prenda ordinaria sobre créditos}

Del mismo modo que la prenda ordinaria sobre bienes corporales se perfecciona mediante la entrega (artículo 2386 del $C$ C), la lógica del desplazamiento ideal del crédito se construye sobre la idea de que el crédito debe quedar fuera del control del constituyente. Las finalidades de la traslación, veremos, son idénticas en uno y otro caso, y sus diferentes caminos no sólo se justifican en atención al carácter inmaterial del objeto prendado sino, también, en la manera por medio de la cual dichos fines pueden ser cumplidos.

Empecemos por los bienes materiales, en los que el objetivo del desplazamiento parece más evidente. La entrega física del bien que perfecciona el contrato de prenda conferirá al acreedor prendario un derecho real sobre el bien prendado, derecho que no le atribuye ninguna de las facultades propias del dominio (ni de desmembramientos del mismo), como tampoco le permite asegurarse del cumplimiento de la obligación garantizada por medio de la apropiación de dicho bien (dada la prohibición de pacto comisorio contenida en el artículo $2397 \mathrm{del} C C$ ). Al contrario, este desplazamiento sólo buscará, por una parte, coaccionar sicológicamente al deudor para que realice el pago de la obligación principal, como único medio para la recuperación del bien por parte del constituyente, y, por la

${ }^{9}$ Sentencia de la Corte Suprema, 13 de diciembre de 1919, disponible en Revista de Derecho y Jurisprudencia, tomo XVIII, Santiago, 1921, sección primera, p. 259. 
otra, la extracción de la cosa prendada del campo de acción de este último para evitar la desaparición o desmejoramiento de la garantía ${ }^{10}$.

En el caso de la prenda ordinaria sobre créditos, la incorporeidad del bien objeto de la garantía evidentemente excluirá un desplazamiento físico, pero sí permitirá la configuración de un cierto "desplazamiento ideal o jurídico". Queremos expresar con lo anterior, más allá de lo impreciso del lenguaje, que el perfeccionamiento de la prenda ordinaria debe suponer que el crédito quedará fuera del control del constituyente para caer en manos del acreedor prendario. En nuestro sistema, ello se logra, precisamente, mediante la privación de las facultades de cobro y recepción del pago por parte del constituyente y su asignación al acreedor prendario. Este desplazamiento ideal, en suma, logrará los mismos efectos sicológicos y protectores que una traslación física. Así, el constituyente sólo podrá recobrar sus facultades de cobro e, incluso, los resultados de un pago ya realizado, si el deudor efectivamente da íntegro cumplimiento a su obligación principal. Y así también se evita la desaparición del resultado del pago, operando una suerte de transferencia de la facultad de cobro a manos del acreedor prendario.

Ahora bien, la forma específica de lograr estos efectos es tratada por el artículo 2389 del $C C$ mediante las dos gestiones antes reseñadas: la entrega del título justificativo del crédito al acreedor prendario y la notificación al deudor del crédito prendado del hecho de la prenda, juntamente con la prohibición de pagar en otras manos que no sean las de aquél. Cabe advertir que, a nuestro juicio, el carácter real del contrato de prenda de créditos no se configura en atención al primero de los requisitos antes señalados ${ }^{11}$. La entrega del título justificativo del crédito sólo cumplirá una finalidad instrumental, puesto que es de esta manera como el acreedor prendario podrá comparecer ante el deudor del crédito prendado (mediante ministro de fe), dándole cuenta de la constitución de la prenda. Pasa a ser, entonces, una prueba fehaciente del desplazamiento, y la forma de comprobar al deudor del crédito prendado que cualquier pago

${ }^{10}$ En contra, Rolf Serick, Garantías Mobiliarias en Derecho alemán, traducción de Ángel Carrasco Perera, Madrid, Tecnos, 1990, p. 77, para quien la exigencia de un acto de entrega deriva del principio de publicidad de la prenda, como medio de exteriorización. En sentido similar, véase Manuel Somarriva Undurraga, Tratado de las cauciones, Santiago, Editorial Nascimento, 1943, p. 246. Nosotros creemos que, de tratarse de una forma de publicidad, esta tendrá sin duda un carácter bastante rudimentario, o, como señalan Michel CABRILLAC, Christian Mouly, Séverine Cabrillac y Philippe Pétel, Droit des Sûretés, Paris, Lexis Nexis Litec, 2007, un carácter inepto para prevenir al público de la existencia de la prenda.

${ }^{11}$ Cfr. Somarriva (n. 10), pp. 245 y 246, quien parece indicar lo contrario al señalar que: "Tenemos entonces que entre acreedor y deudor la prenda se perfecciona por la entrega del título... Respecto de terceros la prenda se perfecciona por la notificación que se hace al deudor del crédito dado en garantía". 
que no se haga en manos del acreedor prendario dejará de ser liberatorio de la obligación. De ahí las semejanzas con la regulación de la cesión de créditos previstas en el artículo 1901 y siguientes del $C C^{12}$.

El punto crítico del desplazamiento ideal se construye, en definitiva, sobre esta prohibición de pago al constituyente y la orden de pago al acreedor prendario. Como complemento, aunque veremos que con escasa precisión jurídica, el artículo 12 del DL 776 dispone que la recepción de tal pago es efectuada por el acreedor prendario a título de representante legal del constituyente.

\section{c. Forma de realización de la prenda ordinaria sobre créditos}

\section{c.1. Planteamiento general}

La regulación contenida en el artículo 2389 del $C C$ omite cualquier referencia expresa a la forma de realización de la prenda sobre créditos, pero otorga un antecedente importante: el pago del crédito será recibido directamente por el acreedor prendario, sin distinción de si la obligación principal se encuentra o no vencida. En caso de tratarse de un crédito dinerario (que constituirá el supuesto más frecuente), no tendría sentido concluir que el hecho del incumplimiento da pie al inicio de una ejecución judicial, en primer término, porque no habrá necesidad de embargo, en tanto el bien objeto de la garantía ya se encuentra en poder del acreedor prendario, y, luego, porque el principal sentido de esta forma de realización es la liquidación del bien conforme a su mayor valor posible, cuestión que no parece ser necesaria de tratarse de tal clase de crédito.

En suma, la mayor virtud de la prenda ordinaria sobre créditos dinerarios es su forma de realización extrajudicial que, conforme al artículo 12 del DL 776, se traducirá en que:

"las cantidades que perciba [el acreedor prendario] las aplicará, sin sujeción a las formalidades de los artículos anteriores, al pago de su propio crédito, si éste fuera de igual naturaleza, y en seguida rendirá cuenta a su deudor”.

Esta misma lógica se deduce del artículo 819 del Código de Comercio, al disponer:

"Si el crédito dado en prenda devenga intereses, el acreedor los imputará al pago de los que se le deban.// Pero si la deuda garantida

${ }^{12}$ De hecho, en nota al margen del artículo 2389 del Código Civil, Andrés Bello hace referencia al actual artículo 1902 en relación con la necesidad de notificación al deudor. 
por la prenda no gana intereses, se aplicarán los que produzca el crédito empeñado en parte de pago del capital asegurado".

Pero bien podría parecer que este mecanismo de realización infringe la lógica de la prohibición del pacto comisorio (artículo 2397 del CC). A estos efectos, cabe responder que la doctrina ha indicado que la razón de la proscripción de este pacto se encuentra tanto en el intento de esquivar el encubrimiento de la usura ${ }^{13}$, como en evitar un detrimento injusto en el patrimonio del deudor, para el caso que el valor del bien prendado sea superior al de la obligación incumplida ${ }^{14}$. Pero ambos riesgos suponen la falta de una valoración objetiva del bien que permita un desequilibrio entre éste y el valor de la obligación garantizada, como también la ausencia de una obligación de parte del acreedor prendario de restituir cualquier eventual exceso al constituyente. En el caso de la prenda de créditos dinerarios, estos dos factores son tomados en cuenta por parte del legislador al tiempo de disponer la fórmula de la imputación como medio de realización de la prenda sobre créditos: la valoración objetiva efectuada por un tercero ajeno a la relación se hace innecesaria, toda vez que bien puede asumirse que el máximo valor que puede tener el crédito dinerario es el monto adeudado; $y$, por su parte, el acreedor prendario siempre estará obligado a rendir cuentas al constituyente, restituyéndole un eventual exceso. En consecuencia, la lógica de esta forma de realización se acerca más al llamado "pacto marciano" que al comisorio ${ }^{15}$.

De tal suerte, la intervención de los tribunales no parece ser útil ${ }^{16}$, salvo que no exista acuerdo entre acreedor prendario y constituyente sobre si se ha producido o no el incumplimiento de la obligación principal, sobre la forma en que se ha llevado a cabo la imputación o sobre la determinación de un eventual exceso al que el constituyente podría tener derecho. De ahí la importancia de la remisión por parte del artículo 12 del DL 776 al procedimiento de rendición de cuentas regulado en el título XII del libro III del Código de Procedimiento Civil.

Ahora bien, debemos profundizar algo más en la relación entre la recepción del pago por parte del acreedor prendario y la forma de reali-

${ }^{13}$ Somarriva (n. 10), p. 271.

${ }^{14}$ Luis Fernando Reglero Campos, "El pacto comisorio", en María Elena Lauroba, Joan MARSAL (eds.), Garantías reales mobiliarias en Europa, Madrid, Marcial Pons, 2006, p. 255.

${ }^{15}$ Para la lógica del "pacto marciano", véase Reglero (n. 14), p. 261 y ss. A su vez, para una referencia a la imputación del crédito como expresión de este pacto, véase CARRASCO, Cordero y Marín (n. 5), p. 284. Dicha posibilidad, dada su objetividad, puede resultar más conveniente que seguir el mecanismo típico de la subasta, dado que en razón de ésta el precio obtenido puede ser bastante menor que su valor nominal.

${ }^{16}$ Véase sentencia de la Corte Suprema, 11 de enero de 1947, disponible en Revista de Derecho y Jurisprudencia, tomo XLV, Santiago, 1948, sección primera, p. 120. 
zación de esta garantía. En primer lugar, creemos necesario aclarar que el acreedor prendario tiene derecho a recibir el pago en virtud del contrato de prenda perfeccionado, que le ha conferido una cierta titularidad (aunque no dominical) sobre el crédito. No es efectivo, como dispone el citado artículo12 del DL 776, que el acreedor prendario obre en carácter de representante legal del constituyente, porque ello implicaría una relación fiduciaria que no tiene por qué serle atribuida. El título que permite al acreedor prendario la recepción del pago no proviene de la ley, como ocurre en un caso de representación legal, ni se funda propiamente en una técnica de protección (común en esta clase de representación), sino en el efecto propio de la prenda real del Código Civil y del Código de Comercio. Así se desprende también del régimen del endoso en garantía en los términos dispuestos por el artículo 30 de la ley $\mathrm{N}^{\mathrm{o}} 18.092$, de 14 de enero de 1982, sobre letras de cambio y pagarés que, sin recurrir al artificio de la representación legal, faculta al portador del documento para ejercer todos los derechos emanados del mismo, cobrarlo judicial y extrajudicialmente y aplicar sin más trámite su valor al pago de su crédito, con obligación de rendir cuenta al endosante.

Sin embargo, la posibilidad de que el acreedor prendario reciba el pago del crédito es una cosa, y el hecho que pueda imputarlo sin más al 10 pago de la obligación garantizada es otra. Puede ocurrir que el crédito garantizado venza antes o después de que el acreedor prendario haya obtenido el pago del crédito prendado, y de ello dependerá la posición que tenga éste sobre las resultas de dicho pago. A continuación revisaremos los diversos supuestos y soluciones legales que estimamos aplicables.

c.2. Supuesto en que la obligación principal se ha extinguido con anterioridad al vencimiento del crédito prendado

La situación más simple es aquélla en la que la obligación principal es efectivamente cumplida por el deudor, mientras el crédito prendado aún no ha vencido. En este caso, la extinción de la obligación principal acarreará el fin de la prenda. Por ello, el deudor del crédito cedido deberá ser nuevamente notificado de que el pago liberatorio ahora sólo podrá hacerse en manos del constituyente.

c.3. Supuesto en que el acreedor prendario ha recibido

el pago del crédito prendado con anterioridad

al vencimiento de la obligación principal

La situación es algo más compleja si el crédito prendado hubiese vencido con anterioridad a la extinción de la obligación principal, y el acreedor prendario hubiese recibido el pago de parte del deudor. En este caso, de 
tratarse de un crédito dinerario, cumplida que sea la obligación principal, el acreedor prendario no podrá efectuar imputación alguna, de modo que estará obligado a restituir el tantumdem al constituyente. De mediar alguna discusión entre las partes de si la obligación principal se ha o no cumplido conforme a sus términos, tal conflicto se resolverá mediando el ejercicio de las correspondientes acciones por parte del constituyente para la correcta rendición de cuentas. Si el tribunal estima que no ha existido incumplimiento, el reembolso será por el total. En caso contrario, el tribunal aceptará el hecho de la imputación y sólo obligará a que se efectúe un reembolso si existiere un sobrante. Finalmente, en caso de que el monto no fuere suficiente como para dar cobertura a todo el crédito garantizado, se deberán seguir las reglas de imputación del pago (artículo 1595 y siguientes del $C C$ ), replicadas de algún modo en el artículo 819 del Código de Comercio.

Pero en este régimen queda aún por resolver qué ocurre si el pago del crédito prendado ha tenido lugar con anterioridad a la época de vencimiento de la obligación principal. Una imputación anticipada para el pago del crédito garantizado puede contravenir los intereses de las partes de igual modo que cualquier forma de pago anticipado. De ahí que parezca más prudente entender que, a menos que haya sido ésta la intención de las partes, se admita que ha operado una subrogación real en el objeto de la prenda, respuesta que ya había sido esbozada incluso en el texto del Digesto antes citado. Esta solución es alcanzada por quienes asumen un régimen paralelo entre la prenda de créditos y una cesión pro solvendo del crédito, en garantía, de modo que ni siquiera la recepción del pago por parte del acreedor prendario hará desaparecer la obligación principal, sino sólo cuando ésta se hubiere incumplido ${ }^{17}$.

Así, de tratarse de una especie no fungible, debe entenderse que, a partir del pago efectuado por el deudor del crédito prendado, la prenda recaerá sobre el bien recibido por el acreedor prendario. Desde dicho momento, serán aplicables en plenitud todas las disposiciones del Código Civil o el Código de Comercio, según sea el caso, respecto a la prenda ordinaria sobre bienes corporales. No será éste un caso de común ocurrencia, dado que la lógica de la prenda de créditos se vincula con mayor fuerza a los créditos de carácter dinerario. Así se desprende también del régimen de realización previsto en el artículo 12 del DL 776 y en el artículo 819 del Código de Comercio, en tanto una imputación sería imposible de tratarse de bienes que no tengan un carácter fungible.

En caso de que el acreedor prendario haya obtenido precisamente el pago de una suma de dinero (u otros bienes fungibles), la subrogación

${ }^{17}$ José Ramón García Vicente, La prenda de créditos, Thomson Civitas, Cizur Menor, 2006, pp. 233 a 238. 
operará de un modo bastante diferente. Parece lógico concluir que, en este caso, si luego el deudor diere efectivo cumplimiento a la obligación principal, el acreedor prendario no debe restituir al constituyente las mismas "monedas" o especies que ha recibido del deudor del crédito prendado, sino otras tantas del mismo género y calidad (en otras palabras, el tantumdem).

Una primera construcción de este supuesto entenderá que la subrogación ha operado de modo que el bien ahora prendado es el dinero (u otro bien fungible), constituyéndose lo que se ha venido en denominar como una "prenda irregular" ${ }^{18}$. Pero esta construcción tiene un obstáculo insalvable: si en virtud de esta clase de negocios, el acreedor prendario ha adquirido el dominio sobre los bienes entregados (de lo que deriva que sólo está obligado a una eventual restitución del tantumdem), no puede entenderse que a la vez tenga un derecho real de prenda sobre bienes que ya le pertenecen.

Por ello se ha planteado una explicación alternativa que nos parece más convincente: la subrogación real no se referirá a los dineros recibidos, sino al propio crédito que, en caso de cumplimiento de la obligación principal, el constituyente tendrá respecto al acreedor prendario para exigir el reembolso de los fondos recibidos por este último ${ }^{19}$. Explicaremos en detalle esta solución porque su enunciación puede resultar confusa. Esta posición supone que, a contar de la recepción del pago por parte del acreedor prendario, el constituyente tendrá un crédito en contra de aquél para la restitución de los fondos que hubiere recibido con motivo de la

${ }^{18}$ La denominación de "prenda irregular" viene dada por la configuración paralela de otros negocios irregulares, como en el depósito, que, versando sobre bienes fungibles, implica la adquisición del dominio por parte del depositario, obligándose sólo a la restitución del tantumdem y no de los objetos particularmente entregados en depósito (artículo 2221 del CC). En este caso, el sistema jurídico hace variar la titularidad real del depositante sobre el dinero originalmente entregado a la titularidad de un derecho personal para exigir el tantumdem al término del contrato. En el caso de la prenda irregular ocurre un tanto similar, con la diferencia que el derecho de crédito sólo surgirá cuando se haya dado estricto cumplimiento a la obligación garantizada. Véase Somarriva (n. 10), p. 230.

Por su parte, Alejandro GuZMán BRITO, "La pignoración de grupos de bienes de una misma clase o universalidades de hecho en la nueva Ley de prenda sin desplazamiento", en Revista de Derecho de la Pontificia Universidad Católica de Valparaíso, No 30, Valparaíso, 2008, p. 95, expresa: "Una prenda con desplazamiento sobre fungibles no es prenda sino un crédito sometido a algunas reglas de la prenda suele llamársela 'prenda irregular'. Las diferencias entre ella y la prenda sobre no fungibles son tales y tan sustanciales, que es desorientador y fuente de confusión afirmar que sigue siendo prenda, en circunstancias que su verdadera naturaleza es la indicada. Acaece al respecto lo mismo que con el cuasiusufructo (artículo 789 del $C$ C.) y el depósito irregular (artículo 2221 del $C C$.), que también son créditos, aunque sometidos a algunas reglas del usufructo o del depósito regular".

${ }^{19}$ Carrasco, Cordero y Marín (n. 5), p. 230. 
prenda, crédito que lógicamente se encontrará sujeto al cumplimiento de la obligación principal. Esta construcción alternativa señala que este nuevo crédito es el que, a contar de la recepción del pago, estará prendado a favor del acreedor prendario.

Así, extinguida que haya sido la obligación principal, caerá también la garantía, de modo que el acreedor prendario deberá hacer entrega del tantumdem al constituyente. Al contrario, si el deudor incumple su obligación principal, deberá procederse de igual manera que respecto a cualquier prenda de créditos, pero con una particularidad. Como en este caso el acreedor prendario es el deudor del crédito prendado (el crédito de restitución), en lugar de proceder al pago (imposible, por tratarse de una misma persona), deberá imputar el monto recibido para la solución de la obligación garantizada. Alguien bien podría decir que, en este caso, la obligación de restitución no ha llegado a ser exigible, por cuanto estaba sujeta a una suerte de condición suspensiva consistente en el cumplimiento de la obligación principal. Y podrá tener razón, pero siempre observando que una obligación de restitución sujeta a esta suerte de condiciones se asemeja enormemente al concepto de la prenda, como también reconoce el artículo 1 del DL $776^{20}$.

Cualquiera sea la explicación que se acepte, en caso de que la obligación garantizada no sea íntegra y oportunamente cumplida y el acreedor prendario impute los dineros recibidos para satisfacerla, no puede hablarse propiamente de compensación porque no hay obligaciones recíprocas entre las partes ${ }^{21}$. En el caso de que el deudor no haya cumplido la obligación principal, el acreedor prendario no está obligado a la devolución del dinero recibido, dado que habrá fallado la condición que obligaba a la restitución. Así, existiendo una sola obligación vigente (la obligación principal incumplida), falta el requisito de reciprocidad como elemento esencial de este modo de extinguir (artículo 1657 del CC). De ahí que sea preferible hablar de imputación (o secum pensatio) para referirse a esta forma de realización, no sólo por una precisión terminológica, sino teniendo particularmente a la vista las limitaciones a la compensación en la legislación concursal (artículo 69 del libro IV del Código de Comercio) ${ }^{22}$.

${ }^{20} \mathrm{El}$ artículo 1 del DL 776 dispone: "Se comprenden en las disposiciones de esta ley toda clase de garantías sobre bienes muebles que se entreguen a un acreedor, sea bajo la forma de una venta condicional, de un pacto de retroventa o de otra manera; sin que valga estipulación alguna en contrario”.

${ }^{21}$ Cuestión que se hace, incluso, más patente si el constituyente de la prenda es una persona distinta que el deudor de la obligación principal.

${ }^{22}$ Considérese que la doctrina comparada entiende que hay cierta cercanía entre la imputación y la compensación, aunque en la primera no se requieren créditos recíprocos. Nos señala María Cruz Moreno, La prenda irregular, Madrid, Colegio de Registradores 


\section{Prenda Sin DesPlazamiento SObre CRÉditos, SU PERFECCIONAMIENTO Y SU FORMA DE REALIZACIÓN \\ a. Lógica de la prenda sin desplazamiento sobre créditos}

Por medio del mensaje presidencial de fecha 30 de junio de 2003, se plantearon al Congreso Nacional una serie de modificaciones legales tendientes a perfeccionar los mecanismos de ahorro e inversión, incentivando principalmente el mejoramiento del mercado de capitales. Dichas reformas se iniciaron con la ley $\mathrm{N}^{\circ} 19.705$, que reguló las ofertas públicas de adquisición de acciones y gobiernos corporativos, seguida por la primera reforma al mercado de capitales contenida en las leyes $\mathrm{N}^{\mathrm{O}} 19.768$ y 19.769 .

La nueva iniciativa, que finalmente se tradujo en la promulgación de la ley $\mathrm{N}^{\mathrm{o}} 20.190$, tenía por finalidad promover el desarrollo de la industria del capital de riesgo y el financiamiento de nuevos proyectos, el abaratamiento de los costos de transacción y contratación comercial sofisticada, la profundización de reformas de perfeccionamiento de administración societaria, el fortalecimiento de los mecanismos de fiscalización, potestades de control, sanción y coordinación, y el perfeccionamiento del mecanismo de ahorro voluntario.

Sobre el tema en particular de la prenda sin desplazamiento, el legislador pretendió otorgar una regulación orgánica unitaria, derogando casi toda la normativa existente sobre la materia, fundamentando lo anterior en las dificultades de la industria del capital de riesgo para acceder al crédito. El Ejecutivo detectó inconvenientes de índole práctico, señalando en su mensaje:

"En primer lugar, como parte del análisis desarrollado con relación al fomento del capital de riesgo, se ha considerado que la mayor o menor facilidad de acceso al crédito es un factor relevante en la generación de nuevos proyectos de inversión. El incentivo a tales inversiones puede lograrse no sólo a través de asistencias o fomento directo, sino que también en virtud de mejoras efectivas en la infraestructura y tecnología contractual que organiza la industria del crédito de otros productos financieros accesorios".

Se estimó acertadamente que las garantías constituyen elementos claves en la industria financiera, dejando en claro que por medio de ellas

de la Propiedad y Mercantiles de España, 1995, p. 221, que: "Antes bien, se trata aquí de que el aumento patrimonial que una persona obtiene se deba imputar al crédito o derecho del que dicha persona sea titular por otro título, y en virtud de dicha imputación, se deba considerar extinguido el derecho y satisfecho su titular". 
se facilita el otorgamiento de créditos, principalmente en razón de la disminución de los niveles de riesgo (de incumplimiento e insolvencia) tolerables por las instituciones crediticias. Sin embargo, no sólo se ha estimado necesario contar con la posibilidad de otorgamiento de tales garantías sino, también, con estructuras legales eficientes por medio de las cuales se cumpla con dicho objetivo. Dicho en otras palabras, la intención del legislador está dada por el interés de facilitar el procedimiento de constitución y realización de las referidas cauciones, protegiendo, en primer término, a la industria crediticia.

Consecuencia de lo anterior, el legislador no opta por reformar las regulaciones existentes por medio de incorporación de modificaciones y supresiones de su articulado, sino que elige derogar íntegramente la normativa anterior, creando una nueva prenda sin desplazamiento, basado en las siguientes ideas fundamentales:

i) la unidad normativa, derogando otros mecanismos de prenda basados en la falta de desplazamiento ${ }^{23}$;

ii) la certeza, reemplazando el mecanismo de publicidad por un sistema registral;

iii) la facilitación de su constitución, permitiendo que el contrato se celebre mediante escritura pública o instrumento privado y

iv) la ampliación de los bienes susceptibles de prenda, incluyendo la posibilidad de pignorar derechos, de inventarios, cuentas por cobrar, contratos, valores y derechos como, asimismo, la posibilidad de constituir prendas sobre grupos de bienes de una misma clase o sobre universalidades de hecho.

Ahora bien, referidos a la ampliación del objeto de las prendas, se ha observado que el desplazamiento ideal del crédito no se ha ajustado bien a las necesidades de los nuevos tiempos, en los que la riqueza muchas veces se encuentra en los flujos de dinero que resultan de la actividad del deudor. De igual manera como la prenda ordinaria sobre bienes corporales fue criticada por la traslación de la tenencia de bienes productivos -generando la necesidad de consagrar nuevos sistemas de prendas sin desplazamiento-, la creatividad forense dio paso a otras estructuras para configurar alguna suerte de garantía sobre los créditos sin que ella prive a su titular de sus facultades previo a un eventual incumplimiento de sus obligaciones. En regímenes basados en una transferencia abstracta de los

${ }^{23}$ Sin embargo, esta unidad normativa no es completa, toda vez que el artículo 42 del artículo 14 de la ley $\mathrm{N}^{\mathrm{o}} 20.190$ no derogó las disposiciones pertinentes de la ley $\mathrm{N}^{\mathrm{O}}$ 4.287 , sobre prenda de valores mobiliarios a favor de los bancos, de la ley $\mathrm{N}^{\circ} 18.690$, sobre almacenes generales de depósito, en lo referido a la denominada "prenda warrant", ni el régimen de las prendas que recaen sobre naves y aeronaves (artículo 5 del artículo 14 de la ley $\left.\mathrm{N}^{\mathrm{o}} 20.190\right)$. 
bienes, como en Alemania, se impuso la idea de una transmisión fiduciaria del crédito ${ }^{24}$. En Francia e Italia, en cambio, se elaboraron mecanismos de cesión condicional de derechos, condición que se entendía referida al cumplimiento de la obligación principal ${ }^{25}$. En el Derecho Comparado, en consecuencia, la prenda de créditos se fue convirtiendo en una figura de amplio estudio doctrinal, pero de escasa utilización práctica.

Pero aun presentándose similares dificultades, estas soluciones no tienen cómoda cabida en el Derecho chileno. El recurso a la cesión fiduciaria puede resultar controvertida en un sistema de transmisión causal de bienes como el nuestro, al tiempo que la cesión condicional bien puede ser recalificada como "prenda", al menos a efectos de su ejecución, conforme a lo dispuesto en el artículo 1 del DL 776. Por su parte, el legislador tampoco ofrecía salida mediante el recurso a los diversos modelos de prenda sin desplazamiento, en tanto éstos sólo se concentraban en los problemas derivados de la traslación de bienes productivos, por lo general, corporales ${ }^{26}$. Específicamente, el segundo inciso del artículo 4 de la Ley No. 18.112, sobre prenda sin desplazamiento, desecha la posibilidad de constitución de esta clase de garantías sobre créditos (como también respecto a cualquier otra clase de bienes incorporales), en tanto dispone: "Podrá constituirse prenda sin desplazamiento sobre toda clase de bienes corporales muebles".

Sin embargo, la realidad de los financiamientos actuales muchas veces requiere que los flujos permanezcan en poder de su titular, por ser el único modo en el que éste puede desarrollar sus negocios. Pero la empresa prestadora de servicios, cuya importancia económica ha ido sin duda en aumento desde hace un buen tiempo, tiene en tales flujos su riqueza más importante (sino, incluso, su única riqueza), y su recurso más útil para obtener financiamiento. La unión de ambos factores ha hecho indispensable la liberación de cualquier traba normativa -porque ideológicamente no parece existir obstáculo a ella- que admita la constitución de una prenda "sin desplazamiento" sobre créditos.

${ }^{24}$ Para un estudio detallado sobre la cuestión en el Derecho alemán, puede consultarse a SERICK (n. 10) passim.

${ }^{25}$ Véase CABRILlaC et al. (n.10), p. 528. En primer término, a modo de cesión sujeta a condición suspensiva, condición que se configuraba bajo el supuesto de hecho de incumplimiento por parte del deudor del crédito principal. Luego, también se ha seguido el mecanismo de cesión sujeta a condición resolutoria, procediéndose a la restitución del crédito una vez cumplida la obligación principal, acercándose a la figura del negocio fiduciario conforme a la teoría del doble efecto.

${ }^{26}$ Para estos efectos, considérense las normas contenidas en el artículo 2 de la ley $\mathrm{N}^{\mathrm{O}}$ 4.097, sobre prenda agraria; el artículo 1 de la ley $\mathrm{N}^{\circ} 4.702$, sobre compraventa de cosas muebles a plazo, y el artículo 24 de la ley $\mathrm{N}^{0} 5.687$, sobre prenda industrial (salvo en lo que respecta la posibilidad de constituir prenda sobre acciones, bonos y otros valores). 
Además, la práctica había dado cuenta de al menos dos situaciones en la que el requisito de la notificación al deudor del crédito prendado devenía en un obstáculo para la estructuración de ciertos negocios de financiamiento: las pignoraciones globales de una masa de créditos y la imposibilidad de constituir prendas anticipadas sobre créditos futuros, cuyos deudores específicos sean aun desconocidos al tiempo de su celebración ${ }^{27}$.

Todas estas cuestiones han pretendido ser resueltas por medio del nuevo régimen contenido en el artículo 14 de la ley $\mathrm{N}^{\mathrm{O}} 20.190$, que aún está a la espera de la dictación y publicación del reglamento del Registro de Prendas sin Desplazamiento para su entrada en vigencia (artículo 41 del referido artículo 14). De este modo, la regulación de este nuevo tipo de prenda debe señalar las consecuencias que el negocio produce ante la falta de un desplazamiento jurídico del crédito prendado. Quiere decir lo anterior que, como resultado de la constitución de prenda registral sobre créditos, el acreedor prendario no necesariamente tiene la posibilidad de la recepción directa del pago del crédito, de modo similar a la pérdida de la tenencia de los bienes físicos como elemento característico de la prenda ordinaria sobre bienes corporales.

\section{b. Perfeccionamiento de la prenda sin desplazamiento sobre créditos}

\section{b.1. Requisitos para el perfeccionamiento \\ del contrato de prenda}

La lógica de la prenda sin desplazamiento sobre créditos, hemos dicho, es que la traslación de las facultades de cobro y recepción del pago no son elementos estructurales o constitutivos del contrato. Por ello, el artículo 7 del artículo 14 de la ley $\mathrm{N}^{\circ} 20.190$ dispone:

"La prenda de créditos nominativos deberá ser notificada al deudor del crédito pignorado, judicialmente o por medio de un notario con exhibición del título, prohibiéndole que lo pague en otras manos, salvo que mediare su aceptación por escrito; y en caso contrario, le será inoponible”.

Cabe advertir, como lo hace expresamente la referida norma, que esta notificación deja de ser un requisito necesario para el perfeccionamiento de la prenda, sino sólo una formalidad para que ésta sea oponible al deu-

${ }^{27}$ Fernando Pantaleón, "Prenda de créditos: nueva jurisprudencia y tarea para el legislador concursal”, en Diario La Ley, Ref. D-316, tomo 6, 1997 (recurso electrónico), disponible en http://la leydigital.laley.es, consultado el 9 de julio de 2010. 
dor del crédito prendado. Además, de no ser así, no existirían diferencias constitutivas entre la prenda ordinaria y la prenda sin desplazamiento de créditos.

La prenda sin desplazamiento se caracteriza, entonces, por ser un contrato solemne, en tanto requiere para su perfeccionamiento que el acuerdo conste en escritura pública o instrumento privado, en cuyo caso, las firmas de las partes concurrentes deberán ser autorizadas por un notario y el instrumento deberá ser protocolizado en el registro del mismo notario que autoriza (artículo 2 del artículo 14 de la ley $\mathrm{N}^{0}$ 20.190). Las menciones mínimas de tal instrumento se establecen en el artículo 3 del mismo artículo 14, y son las siguientes:

i) la individualización de sus otorgantes;

ii) la indicación de las obligaciones caucionadas o bien de que se trata de una garantía general;

iii) la individualización o la caracterización de las cosas empeñadas; $\mathrm{y}$

iv) la suma determinada o determinable a la que se limitare la prenda o la proporción en que debiere caucionar diversas obligaciones, si fuere el caso.

Adicionalmente, y sólo respecto a la prenda de créditos nominativos, el artículo 7 antes citado agrega:

"Una copia del título que consigne el crédito nominativo que se otorgue en prenda será protocolizada al tiempo de suscribirse el contrato de prenda y en éste deberá hacerse mención de la protocolización de aquél”.

Todas estas solemnidades son formalidades que la ley ha exigido en atención a la naturaleza del acto o contrato, de modo que su incumplimiento acarreará la sanción de la nulidad absoluta (artículo 1682 del CC). Como señala Fabián Elorriaga, particularmente respecto a la protocolización y su mención en el contrato de prenda, no se tratan de formalidades de publicidad, por cuanto se satisfacen mediante la correspondiente notificación al deudor del crédito prendado (respecto a éste) y, respecto a terceros, mediante la inscripción del contrato en el Registro de Prendas sin Desplazamiento (artículo 25 del artículo 14 de la ley $\left.\mathrm{N}^{\mathrm{o}} 20.190\right)^{28}$.

${ }^{28}$ Fabián Elorriaga de Bonis, "La prenda de créditos nominativos en la nueva normativa de la prenda sin desplazamiento", en Carlos PizArro WiLSON (coord.), Estudios de Derecho Civil IV, Jornadas Nacionales de Derecho Civil celebradas en Olmué, Santiago, Legal Publishing Chile, 2008, p. 555. 
b.2. Requisito para el nacimiento del derecho real de prenda

Ahora bien, perfeccionado el contrato entre las partes, éste sólo constituirá el título para la adquisición del derecho real de prenda. A efectos de realizar su tradición, será necesario proceder a la inscripción del contrato en el señalado registro. Como dispone el citado artículo 25:

"El derecho real de prenda se adquirirá, probará y conservará por la inscripción del contrato de prenda en el Registro de Prendas sin Desplazamiento".

Este nuevo sistema de publicidad se entiende un avance respecto al contemplado en la derogada ley $\mathrm{N}^{\circ}$ 18.112. Como señala el mensaje de la ley $\mathrm{N}^{\mathrm{O}} 20.190$ :

"las prendas agrarias, industrial y de venta de cosas muebles a plazo, si bien no requieren la entrega física de la cosa prendada, tienen diversas limitaciones derivadas del tipo de bienes y negocios a las que se aplican. La Ley de prenda sin desplazamiento, que es la más moderna y amplia, contiene también ciertas rigideces y limitaciones. En efecto, la forma en que se realiza la publicidad de esta Ley es mediante la publicación de un extracto de la escritura del contrato en el Diario Oficial, los días $1^{\circ}$ ó 15 de cada mes, con lo cual el acreedor prendario debiera revisar la totalidad de la publicación antes mencionada para asegurarse que el bien no tenga otros gravámenes anteriores. Lo anterior se traduce en mayor incertidumbre para el acreedor prendario, y por ende, eleva el costo de financiamiento para los proyectos de inversión”.

\section{b.3. Posición del acreedor prendario considerando}

la posibilidad de que la prenda sea aún inoponible al deudor del crédito prendado

Cabe advertir que de esta estructura, en la que la prenda puede ser inoponible al deudor del crédito prendado, resultará que el acreedor prendario no habrá obtenido aún un control absoluto sobre aquél, cuestión que no es de extrañar si se compara con la posición que tendría si la prenda hubiese recaído sobre un bien de naturaleza corporal. No puede ser más evidente: habiendo señalado que uno de los objetivos principales del desplazamiento en la prenda ordinaria consiste en ser una medida de protección del acreedor prendario, su ausencia implica que el ordenamiento jurídico y los particulares deberán precaver los riesgos implícitos 
en tal falta de control, y solucionarlos mediante mecanismos diversos a la traslación del bien.

Corresponderá primeramente a los particulares regular fórmulas convencionales de protección a efectos de salvaguardar los intereses del acreedor prendario. En el caso de prenda sobre créditos, estas medidas normalmente implicarán la necesidad de obtener autorizaciones para que el constituyente convenga modificaciones sustantivas del crédito, establecer obligaciones de información sobre los niveles de pago y morosidad de los deudores de los créditos prendados (en especial tratándose de prendas sobre masas de créditos), impedir la aceptación de pagos anticipados, entre otras. Como complemento a lo anterior, y a modo de fortalecimiento de este régimen, siempre podrá recurrirse a los supuestos de responsabilidad civil contemplados en el artículo 18 y siguientes del artículo 14 de la ley $\mathrm{N}^{0} 20.190$, si bien sus términos generales se centran en la protección de las garantías que recaen sobre bienes corporales, como también a los tipos penales consagrados en el artículo 39 del señalado artículo $14^{29}$.

Sin embargo, estas ideas no deben suponer que, previo al cumplimiento de las formalidades de publicidad, el acreedor prendario no goza de derecho alguno. Si así fuere, la práctica llevaría a tal acreedor a exigir que se practique la notificación de la prenda o se obtenga a priori la aceptación 20 del deudor del crédito prendado, acercando peligrosamente la figura a la concepción inicial de la prenda ordinaria. Al contrario, creemos que la cuestión debe analizarse desde la perspectiva de considerar que, perfeccionado el contrato y cumplidas sus formalidades de inscripción, el acreedor prendario ya habrá obtenido la constitución de un derecho real sobre el crédito objeto de la prenda, lo que le otorga una cierta titularidad sobre el mismo que no puede ser desconocida. En estos términos, el constituyente no puede admitir ni estipular modificaciones al crédito prendado que resulten en un deterioro de las posibilidades de pago del acreedor prendario, dado que ello no lesiona una expectativa de cobro, sino directamente un derecho real ya constituido. De hacerlo (v.gr., extendiendo los plazos, aceptando pagos anticipados, liberando garantías, etc.), el ordenamiento jurídico debe reaccionar, al menos, concediendo al acreedor prendario la posibilidad de exigir el cumplimiento anticipado de la deuda principal recurriendo a los términos generales del número 2 del artículo 1496 del $C C$ y específicos del inciso tercero del artículo 18 del artículo 14 de la ley $\mathrm{N}^{\mathrm{o}} 20.190$.

${ }^{29}$ Véase Alejandro GuZMán BRITO, "La prenda sin desplazamiento de cosas corporales e incorporales futuras", en Revista de Derecho de la Pontificia Universidad Católica de Valparaíso, No 31, Valparaíso, 2008, pp. 252-253. 


\section{c. Forma de realización de la prenda sin desplazamiento sobre créditos}

\section{c.1. Planteamiento del problema}

He aquí un punto que parece bastante confuso en el ámbito de la prenda sin desplazamiento sobre créditos, en cuanto los artículos 7 y 31 del artículo 14 de la ley $\mathrm{N}^{\mathrm{o}} 20.190$ parecen encubrir la existencia de dos mecanismos de realización contrapuestos. El artículo 7 antes citado previene que, a contar de la notificación efectuada al deudor del crédito prendado, o de su aceptación escrita, existirá una "prohibición de pagar en otras manos", frase que, utilizando la misma fórmula que la señalada en el artículo 2389 del $C C$ respecto a la prenda ordinaria de créditos, debe entenderse como una prohibición de pago en otras manos que las del acreedor prendario ${ }^{30}$. Sin perjuicio de que la citada norma no haga referencia expresa a un mecanismo de realización, cabe sospechar de la existencia de un modo extrajudicial de ejecución de la garantía en tanto debe admitirse que desde el momento que la prenda es oponible al deudor del crédito prendado, éste está obligado a efectuar el pago correspondiente en manos del acreedor prendario.

Sin embargo, el artículo 29 del artículo 14 de la ley $\mathrm{N}^{\mathrm{o}} 20.190$, dispone un procedimiento de realización necesariamente judicial, expresando:

“para el cobro judicial de la obligación caucionada, la prenda será realizada de acuerdo con las reglas del juicio ejecutivo en las obligaciones de dar establecidas en el Título I del Libro III del Código de Procedimiento Civil, con las modificaciones que se señalan en los artículos siguientes",

norma que no tiene excepción respecto a la prenda sobre créditos, sino en cuanto el artículo 31 dispone de ciertas características especiales del procedimiento. Sobre el particular, el señalado artículo parte de la base que

“podrá el ejecutante pedir que el embargo se notifique por cédula al deudor del crédito pignorado, a fin que retenga y consigne en la cuenta corriente del Tribunal la suma que éste determine”,

para luego dar cuenta del régimen que deriva de su incumplimiento y oposición.

${ }^{30}$ Elorriaga (n. 28), p. 557. Considérese, además, que el artículo 2556 del Proyecto Inédito del Código Civil aclaraba, al final del texto, que se refería a “...otras manos que las del acreedor prendario" (el énfasis es nuestro). 
La compatibilización de estas dos disposiciones parece difícil, pero pretendemos aclarar este punto distinguiendo la posición que tendrá cada una de las partes involucradas según si ha mediado o no la notificación o aceptación a la que se refiere el artículo 7 del artículo 14 de la ley $\mathrm{N}^{\mathrm{O}}$ 20.190 , esto es, según si la prenda es oponible o no al deudor del crédito prendado.

\section{c.2. Supuesto de inoponibilidad de la prenda al deudor del crédito prendado}

Un primer supuesto se refiere al caso en que el contrato de prenda haya sido perfeccionado y que también haya nacido el derecho real de prenda por haber mediado la correspondiente inscripción, pero que no se haya procedido a la notificación ni aceptación por parte del deudor del crédito prendado. Dado que estas formalidades ya no son requisitos constitutivos de la prenda sobre créditos, su ausencia implicará que el señalado deudor sigue estando obligado a efectuar el pago en manos del constituyente.

De hecho, si no han mediado las citadas formalidades de oponibilidad, el pago efectuado por el deudor del crédito prendado al constituyente extinguirá el crédito, y, en consecuencia, la prenda. Por ello, pese a los 22 términos absolutos en que parece estar redactado el inciso tercero del artículo 18 del artículo 14 de la ley $\mathrm{N}^{\mathrm{O}} 20.190$, la extinción del crédito prendado no siempre implicará el vencimiento anticipado del crédito asegurado. Por ejemplo, si el crédito prendado tiene una vigencia inferior a la del crédito garantizado, el acreedor prendario debe haber considerado la posibilidad de la extinción al tiempo de aceptar que la prenda recayera sobre aquel crédito, de modo que la pérdida de objeto de su caución le era enteramente previsible.

Ahora bien, en caso de que la obligación principal fuese incumplida, no hay impedimento lógico para que se proceda conforme dispone el artículo 31 del artículo 14 de la ley $\mathrm{N}^{\circ} 20.190$. De este modo, se solicitará al tribunal que se proceda al embargo del crédito, y que éste sea notificado al deudor del crédito prendado a efectos que proceda a retener los fondos y consignarlos en la cuenta corriente del tribunal. Como bien señala Fabián Elorriaga, esta solución parte de la base de que se trata de una obligación actualmente exigible y dineraria, pero no creemos que se deba caer en la idea de que el crédito pignorado será subastado de modo ineludible ${ }^{31}$. Así, debemos subdistinguir dos nuevos supuestos:

i) Si el deudor del crédito prendado obedece las órdenes judiciales y procede a retener los fondos y consignarlos en la cuenta corriente

${ }^{31}$ Elorriaga (n. 28), pp. 558-560. Así, también, GuZmán Brito (n. 29), p. 243. 
del tribunal, aún incumplida la obligación principal, no deberá procederse a la subasta del crédito que, incluso, se habrá extinguido por el hecho de la referida consignación.

En consecuencia, superados los eventuales trámites de oposición a la ejecución, y desechadas las correspondientes excepciones, creemos que el tribunal debería hacer entrega de tales fondos al acreedor prendario hasta completar el monto del crédito insatisfecho, lógica que ya se encuentra contemplada en los artículos 253.3 y 511 del Código de Procedimiento Civil.

ii) En caso de que el deudor del crédito prendado no dé cumplimiento a las órdenes judiciales antes señaladas, se procederá conforme al inciso segundo del artículo 31, que dispone:

"Si el obligado a la retención no cumpliere con lo ordenado, el Tribunal, a solicitud del acreedor prendario, despachará en su contra mandamiento de ejecución y embargo".

Ello implica que ni siquiera en este caso se procederá a la subasta del crédito prendado, sino al embargo de bienes suficientes del deudor del crédito prendado para que, producto de su liquidación, se proceda al pago de dicho crédito.

La subasta de un crédito nominativo no tiene sentido si fuere dinerario y actualmente exigible. Así, si el deudor del crédito prendado está dispuesto a pagar, la lógica de la subasta sólo implicaría generar costes de transacción inútiles, por cuanto al monto a obtener del remate (que a lo más sería equivalente a la suma del crédito prendado) se le restarían todos los gastos de la ejecución forzosa. Por su parte, si el deudor del crédito prendado no estuviese dispuesto a pagar, los eventuales postores -de haberlos- considerarían tal contingencia como la "adquisición de un litigio futuro", de manera que el valor del crédito subastado sería tan ínfimo que el mecanismo de realización sería aun perjudicial para el acreedor prendario. Incluso, es difícil pensar en la asistencia de demasiados postores por la ausencia de un verdadero mercado de esta clase de activos.

No obstante, cuando el crédito no es actualmente exigible al tiempo del incumplimiento de la obligación principal, el acreedor prendario puede desear adelantar la recepción de fondos solicitando al tribunal la cesión forzada del crédito, probablemente aplicando una cierta tasa de descuento para su valoración. Por ello, sólo en caso que el acreedor prendario efectivamente desee anticipar los resultados que -de otro modo- puede obtener del crédito por su valor total, cabría recurrir al mecanismo de la subasta para obtener el mayor valor en la realización de tal crédito (con la menor tasa de descuento posible). El remate, hemos dicho, es una fórmula por medio de la cual se 
puede asegurar de algún modo que el bien será enajenado conforme a su valor objetivo, entendiendo por tal, la valoración del mercado.

Sin embargo, no parece prudente concluir que, en atención a la falta de desplazamiento jurídico como elemento constitutivo de la prenda sin desplazamiento de créditos, la retención en cuenta del tribunal y la subasta del crédito sean los únicos mecanismos para la realización de la garantía. Por ello es que creemos que siempre existe la posibilidad de recurrir a la fórmula de la imputación, como describiremos en el supuesto inmediatamente siguiente.

\section{c.3. Supuesto de oponibilidad de la prenda al deudor del crédito prendado}

Un segundo caso supone que se haya procedido a la notificación de la prenda al deudor del crédito prendado o se haya obtenido su aceptación escrita de la garantía. Adviértase que la prenda puede pasar a ser oponible al citado deudor en cualquier tiempo, sea al inicio o en el trascurso de la relación obligatoria, logrando el desplazamiento jurídico del crédito en exactamente los mismos términos que los previstos para la prenda ordinaria. La diferencia no está en que, en el caso de la prenda sin desplazamiento, esta traslación sea imposible, sino sólo en que no es requisito de 24 perfeccionamiento, ni, en consecuencia, consustancial al contrato.

Así, no parecen existir obstáculos para que, incumplida que sea la obligación principal, el acreedor prendario solicite que se lleve a cabo la correspondiente notificación a efectos de impedir que el deudor efectúe el pago en manos del constituyente, estando legalmente obligado a cumplir en las suyas, en los términos señalados en el artículo 7 del artículo 14 de la ley $\mathrm{N}^{\mathrm{o}} 20.190$.

Produciéndose la traslación del crédito en los mismos términos que los previstos en el artículo 2389 del $C C$, puede colegirse una misma lógica de realización. Si el acreedor prendario ha de recibir directamente el pago del crédito, no siempre será necesario el inicio de las acciones judiciales destinadas a su embargo. Además, de tratarse de un crédito dinerario como el que supone el artículo 31 antes citado, tampoco será indispensable recurrir a la lógica de la pública subasta, por los mismos motivos señalados en el supuesto anterior. De no ser de este modo, el acreedor prendario, aun habiendo recibido directamente los dineros objeto del crédito prendado, debería hacer entrega de ellos al tribunal a efectos de proceder a un mecanismo de realización consistente en una absurda "subasta de dinero" 32 .

${ }^{32}$ Evidentemente, estas ideas son sólo aplicables a un supuesto de prenda de crédito dinerario. De recaer sobre cualquier otro bien, la lógica de la imputación es imposible, 
De este modo, recibiendo directamente los fondos, creemos que el acreedor prendario siempre podrá imputarlos al pago de su crédito, debiendo rendir cuentas de su actuación ante el constituyente. En el evento de que este último no esté de acuerdo en que se ha producido un incumplimiento de la obligación, deberá solicitar al acreedor prendario la restitución del tantumdem recibido. En suma, se tratará del mismo mecanismo de realización que el contemplado en el artículo 12 del DL 776 y en el artículo 819 del Código de Comercio.

Cabe advertir que este supuesto parece ser el caso más probable, por cuanto es el que ha justificado la nueva regulación de la prenda sin desplazamiento sobre créditos. De hecho, es el que supone que los flujos de dinero son indispensables para el ejercicio de los negocios del constituyente, y el que admite la prenda de créditos futuros (artículo 9 del artículo 14 de la ley $\left.\mathrm{N}^{0} 20.190\right)^{33}$ y masas de créditos (artículo 11 del mismo artículo 14$)^{34}$. Así también se traslada el momento de notificación al deudor del crédito prendado al tiempo de la ejecución de la prenda, impidiendo que, en razón de la garantía, éste último asuma una noción sobre el estado de los negocios del constituyente.

Paralelamente, cabe señalar que una de las principales ventajas de las prendas sobre créditos dinerarios proviene precisamente de la reducción de los costes de ejecución, dado que no es necesario acudir siempre a un procedimiento de ejecución judicial ${ }^{35}$. Por ello, la alternativa de recurrir a una forma de imputación de los dineros recibidos del deudor del crédito prendado por parte del acreedor prendario no sólo parece lógica -aun faltando el desplazamiento ideal como requisito constitutivo de la prenda-sino, también, imperiosa para que los operadores económicos hagan uso efectivo de esta forma de garantía.

En consecuencia, la necesidad de proceder a la intervención de los tribunales por medio del procedimiento contemplado en el artículo 31 del artículo 14 de la ley $\mathrm{N}^{\mathrm{o}} 20.190$, cuando ya se haya procedido a la notificación, sólo parecería tener algún sentido en caso de que el deudor del crédito prendado se negare a cumplir su obligación en manos del acreedor prendario, aun cuando este supuesto sólo aparezca nítidamente en sus

debiendo procederse conforme a la idea de subrogación real de la prenda, aplicando el procedimiento ordinario de ejecución contemplado en el artículo 29 y ss. del artículo14 de la ley $\mathrm{N}^{\mathrm{o}} 20.190$.

${ }^{33}$ Véase GuZmán Brito (n. 29), p. 229. Para este autor, tienen el carácter de crédito futuro aquéllos que "no existen en Derecho, pero se espera que existan, mas no sólo como algún día posibles, ni como bienes futuros, sino según cierta previsión concreta”. Sólo así, agrega, es posible su determinación al tiempo de la constitución de la garantía.

${ }^{34}$ Véase Guzmán Brito (n. 18), p. 74.

${ }^{35}$ García Vicente (n. 17), p. 143 y ss. 
incisos segundo y tercero, o cuando se quisiere anticipar la recepción del valor del crédito no exigible, previa aplicación de la correspondiente tasa de descuento.

\section{Conclusiones}

La utilización de la prenda de créditos tiene cada vez mayor importancia si se atiende a que la verdadera riqueza de las empresas se encuentra en sus flujos, como parte del fenómeno de la desmaterialización de la economía. Sin embargo, su regulación tradicional se hacía insuficiente ante los nuevos desafíos de los financiamientos. Siguiendo la tradición histórica y comparada, la codificación chilena situó a la prenda de créditos en el ámbito de una garantía calificada como contrato real, constituyendo la entrega del objeto prendado el elemento destinado a la protección del acreedor prendario. Siendo el traslado físico un imposible en relación con el crédito, se opta por el símil de la transferencia de la titularidad para su cobro, a objeto de salvaguardar la garantía y mantener en custodia el bien recibido (prenda propiamente tal) u obligándose a restituir otras tantas de igual género y calidad.

$26 \quad$ La regulación ofrecida por la ley $\mathrm{N}^{\mathrm{o}} 20.190$ ha intentado resolver las dificultades que envuelve la pérdida de las facultades de cobro, y lo hace por medio de un sistema que, si bien a primera vista parece bastante similar al existente, trata la notificación al deudor del crédito prendado como requisito de mera oponibilidad de la prenda, de lo que resulta una falta de desplazamiento jurídico como elemento central de la garantía. Habida cuenta de dicha mutación, resulta no sólo un beneficio para el constituyente sino para la estructuración del negocio en todos aquellos casos en que no es indispensable un nivel de control tan exhaustivo por parte del acreedor prendario o, al menos, no es indispensable ab initio.

Ahora bien, creemos que la citada ley $\mathrm{N}^{\circ} 20.190$ tiende a ser un tanto confusa en relación con los mecanismos de ejecución de la garantía. El hecho de que la notificación o aceptación del deudor del crédito prendado no sea elemento constitutivo de la prenda -sino de mera oponibilidad- no implica que, obtenidos que sean, no pueda seguirse el mismo procedimiento de imputación reflejado en el artículo 12 del DL 776 y en el artículo 819 del Código de Comercio, como medio extrajudicial de realización de prendas que recaen sobre créditos dinerarios. La regulación de un procedimiento judicial para esta clase de créditos parece más bien superflua, y sólo parece tener alguna lógica en caso de que:

i) el crédito prendado no sea actualmente exigible al tiempo del incumplimiento de la obligación principal, de modo que se recu- 
rra a su subasta para que aquél sea descontado, adelantando la recepción de su valor;

ii) cuando pese a haberse notificada la prenda, o ésta haya sido aceptada por escrito, el deudor del crédito prendado se negare a cumplir con la prohibición de pagar en otras manos que no sean las del acreedor prendario, como reza el artículo 7 del artículo 14 de la ley $\mathrm{N}^{\circ} 20.190$ o

iii) cuando no se haya practicado la correspondiente notificación del embargo del crédito prendado de conformidad al artículo 31 del artículo 14 de la ley $\mathrm{N}^{\mathrm{o}} 20.190$, y el deudor del crédito prendario no dé cumplimiento a las órdenes judiciales de retención de fondos y consignación en la cuenta corriente del tribunal.

\section{BiBLIOGRAFÍA}

Aranda Rodríguez, Remedios, La prenda de créditos, Madrid, Marcial Pons, 1996. Cabrillac, Michel, Christian Mouly, Séverine Cabrillac et Philippe Pétel, Droit des Sûretés, Paris, Lexis Nexis Litec, 2007.

Carrasco Perera, Ángel; Encarna Cordero Lobató y Manuel Jesús Marín LÓPEZ, Tratado de los Derechos de Garantía, Pamplona, Aranzadi, 2008, tomo II.

Cruz Moreno, María, La prenda irregular, Madrid, Colegio de Registradores de la Propiedad y Mercantiles de España, 1995.

Elorriaga de Bonis, Fabián, "La prenda de créditos nominativos en la nueva normativa de la prenda sin desplazamiento", en Carlos PIZARRo WiLSON (coord.), Estudios de Derecho Civil IV, Jornadas Nacionales de Derecho Civil celebradas en Olmué, Santiago, Legal Publishing Chile, 2009.

García Vicente, José Ramón, La prenda de créditos, Cizur Menor, Thomson Civitas, 2006.

GuZmán Brito, Alejandro, "La pignoración de grupos de bienes de una misma clase o universalidades de hecho en la nueva Ley de prenda sin desplazamiento", en Revista de Derecho de la Pontificia Universidad Católica de Valparaíso, $\mathrm{N}^{\mathrm{o}}$ 30, Valparaíso, 2008.

GuZmán Brito, Alejandro, "La prenda sin desplazamiento de cosas corporales e incorporales futuras", en Revista de Derecho de la Pontificia Universidad Católica de Valparaíso, No 31, Valparaíso, 2008.

Pantaleón, Fernando, "Prenda de créditos: nueva jurisprudencia y tarea para el legislador concursal", en Diario La Ley, Ref. D-316, tomo 6, 1997, (recurso electrónico), disponible en http://la leydigital.laley.es, consultado el 9 de julio de 2010.

Pothier, Robert Joseph, Tratado del contrato de peño, traducido al español con notas de Derecho Patrio por una sociedad de amigos colaboradores, Barcelona, J. Roger Editor, 1845. 
(0) Reglero Campos, Luis Fernando, "El pacto comisorio", en María Elena Lauroba, Joan Marsal (eds.), Garantías Reales Mobiliarias en Europa, Madrid, Marcial Pons, 2006.

Serick, Rolf, Garantías Mobiliarias en Derecho Alemán, traducción de Ángel Carrasco Perera, Madrid, Tecnos, 1990.

Somarriva Undurraga, Manuel, Tratado de las cauciones, Santiago, Editorial Nascimento, 1943. 